Elsevier required licence: (C) <2019>. This manuscript version is made available under the CC-BY-NCND 4.0 license http://creativecommons.org/licenses/by-nc-nd/4.0/

The definitive publisher version is available online at [http://doi.org/10.1016/j.tej.2019.05.017] 


\title{
The times they are a changin': current and future trends in electricity demand and supply
}

\author{
Alan Rai, Ryan Esplin, Oliver Nunn \& Tim Nelson* \\ Level 5, 201 Elizabeth Street \\ Sydney, NSW, 2000 \\ April 2019
}

\begin{abstract}
The increasing penetration of variable renewable electricity generation in Australia's National Electricity Market over the past decade has led to a sustained change in the shape of electricity demand. In particular, intra-day demand has become more volatile, with demand in some Australian regions increasingly resembling the widely-cited 'duck curve' or more appropriately the 'emu curve'. The changes in demand have, in turn, economically driven out generators whose technical characteristics are ill-suited to supplying this demand profile: high capacity-factor, slow-start plant. In this article, we describe the changes to date in the profile of electricity demand, and draw on other studies to argue that these trends are likely to accelerate going forward based on projected future uptake of variable renewables. In combination with technological and policy developments, these trends imply that flexible plant, such as peaking gas, hydro, and dispatchable storage, are likely to be better suited to the changing profile of demand, in contrast to slow-start and relatively inflexible technologies such as coal and combined-cycle gas plants. These trends are based on the flexibility of different generation technologies and their interaction with emissions considerations.
\end{abstract}

Keywords: electricity markets; energy policy

JEL Codes: D40; D20; D22; O13; Q40; Q41; Q42; Q47; Q48

\section{Introduction}

The past decade has seen a dramatic increase in the penetration of wind and solar PV - the only two mainstream forms of variable renewable energy (VRE) generation in Australia - in Australia's National Electricity Market (NEM). Over the year to July 2007, small- and utilityscale wind and solar PV comprised less than 1 per cent of NEM generation, compared to around 10 per cent over the year to July 2018 (AER, 2018). In South Australia, the NEM region with the highest penetration of VRE generation, the share of small- and utility-scale VRE generation was over 50 per cent over 2017/18, compared to 9 per cent over 2007/08. Across regions and nations, South Australia has one of the highest VRE penetrations in the world, exceeded only by Denmark (Figure 1).

This surge in VRE penetration has been driven by a combination of declining costs for VRE generation - initially wind, but more recently solar PV - and policies aimed at reducing the emissions intensity of electricity generation. Today, the cheapest form of new generation technology in Australia is wind on a levelised cost of electricity (LCOE) basis, though solar PV is expected to overtake wind as the cheapest form of electricity generation (BloombergNEF, $2018 \mathrm{~b}$ ). However, wind and solar PV generation are not perfectly correlated with demand and so output from these plant must be 'firmed' to ensure demand can be met when this variable generation is not available.

The increasing penetration of VRE generation has led to a sustained change in the shape of daily residual electricity demand, both across days and within any given day. In the context of this

\footnotetext{
- Alan Rai and Oliver Nunn are both Senior Economist - Strategy and Economic Analysis at the Australian Energy Market Commission (AEMC). Tim Nelson is Executive General Manager - Strategy and Economic Analysis at the AEMC and an Associate Professor at Griffith University. The authors thank Joseph Nunez - Quantitative Analyst in the AEMC's Strategy and Economic Analysis team - for his assistance. All views, errors and omissions are entirely the responsibility of the authors, not the AEMC or Griffith. Correspondence to alan.rai@aemc.gov.au.
} 
article, residual demand is defined as the demand that needs to be supplied by dispatchable generators such as coal, gas and hydro after accounting for VRE generation.

\section{Figure 1: VRE penetration in selected countries and jurisdictions}

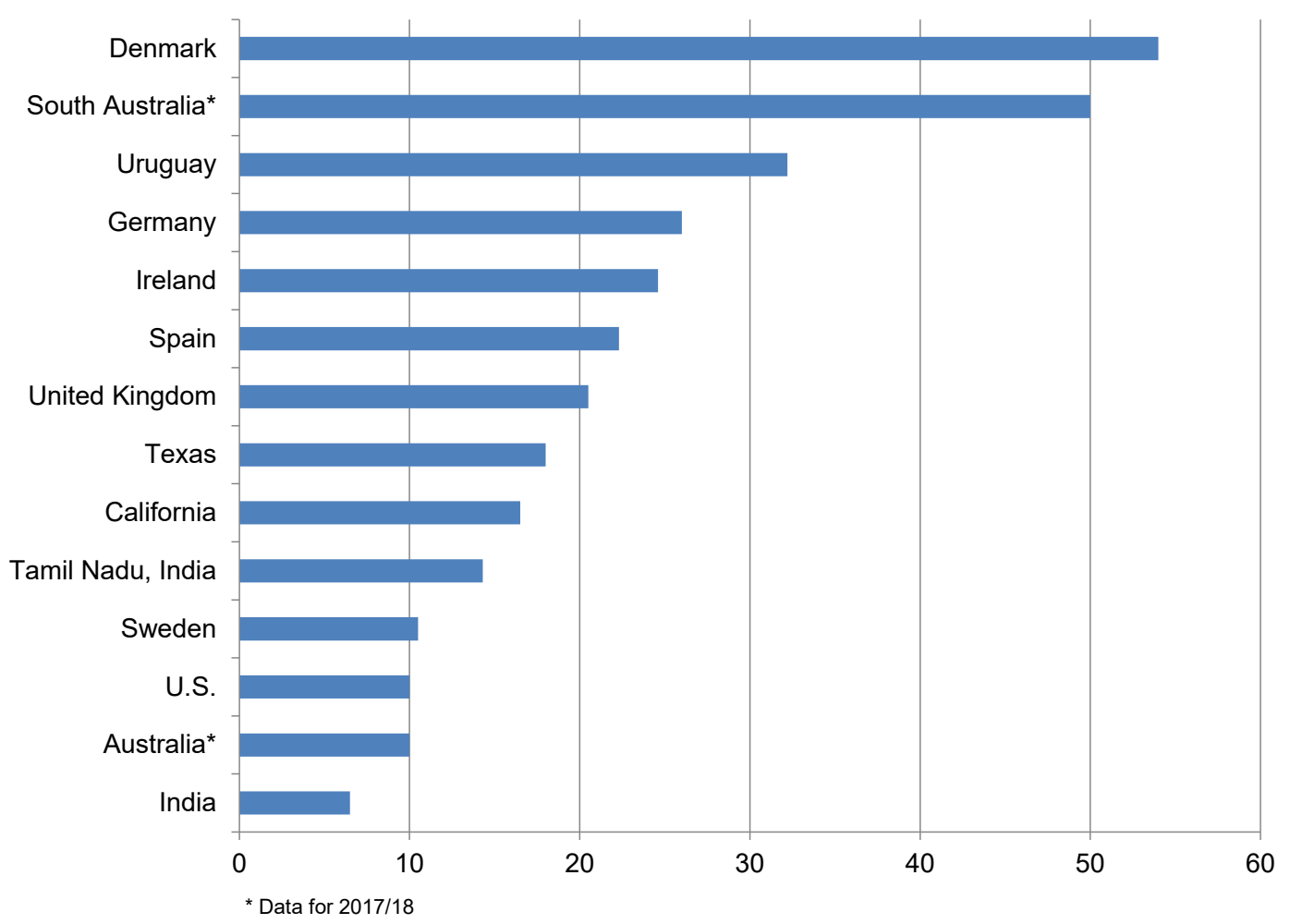

Sources: AEMO; IEEFA (2018); IEA (2017)

Intra-day residual demand has become more volatile, with demand in some Australian regions increasingly resembling the widely-cited 'duck curve'. Furthermore, intra-day demand has become peakier as the increasing penetration of VRE generation has had less of an impact on maximum demand compared to both average and minimum demand. Meanwhile, demand over different days - even within the same season - has become more volatile, as output from behindthe-meter rooftop solar PV has varied.

In this article, we describe the changes to date in the profile of electricity demand. These changes in demand have had, and are having, profound impacts on the mix of dispatchable generation technologies that satisfy this demand. Over the last few years, there has been an exit of generators whose technical characteristics are ill-suited to supplying this demand profile: high capacityfactor, slow-start plant such as black and brown coal plants, and combined cycle gas plants.

This paper is structured as follows. Section 2 presents data on past and projected future VRE uptake in the NEM, and the resulting impact on the profile and level of residual electricity demand. Changes in the shape of residual demand have implications for the types of electricity generation technologies that may be viable going forward. Section 3 discusses the key technological and policy developments that are expected to accelerate the shift towards relatively fast-start and flexible generation technologies. Section 4 discusses how changes to South Australia's residual demand has increased the cost associated with 'firming' variable renewables, and Section 5 concludes with a brief discussion of the implications of these trends in demand and supply for investors in new generation capacity. 


\section{Changes in electricity demand and supply in the NEM}

In recent years we have observed the following three trends that have implications for the nature of electricity demand in the NEM:

1. Increase in utility-scale (i.e. defined as capacity of $100 \mathrm{~kW}$ or greater) VRE generation capacity

2. Rapid up-take of small-scale VRE generation capacity (defined as capacity less than 100 $\mathrm{kW}$ ), which is principally behind-the-meter rooftop PV

3. Minimal growth in aggregate electricity consumption

Each of these trends have implications for the viability of existing generation, and implications for the optimal investment in future generation, as discussed below.

\subsection{Changes in the utility-scale generation mix}

Recent years have seen a significant increase in the installed capacity of VRE generation across the NEM. In 2018 alone, more than 4,000 MW of VRE capacity was added to the NEM (Figure 2). This has been driven by a combination of:

1. Declining costs of VRE generation, of which wind and solar PV have the lowest levelised costs of electricity (LCOE)s. Between 2014 and 2018, the period over which VRE uptake grew rapidly, wind's LCOEs halved (from $\$ 160 / \mathrm{MWh}$ to $\$ 80 / \mathrm{MWh}$ ), while utility-scale PV's LCOE fell by three quarters (from $\$ 315 / \mathrm{MWh}$ to $\$ 85 / \mathrm{MWh}$ ) (BloombergNEF, 2018a).

2. Renewable energy policies, chiefly the Large-scale Renewable Energy Target (LRET) which has existed since 2001. The LRET obligates retailers to buy certificates equal to the annual targets for electricity generated from renewables. The renewable energy target was set at 9.5 terawatt hours (TWh) by 2010 (Simshauser and Nelson, 2013). In January 2011, a target of 41 TWh by 2020 was set, but in June 2015 was subsequently revised down to 33 TWh by 2020. This annual amount remains in place through to 2030, which is when the LRET is scheduled to end (CER, 2018).

Between 2012 and 2017, almost 4,200 MW of coal (black + brown) generation exited (Figure 2). As noted by Simshauser (2018), an increasing penetration of low short-run marginal cost VRE generation pushes down spot prices and requires incumbent generators to adjust their output to complement the variability in VRE generation. Both of these effects reduce the profitability of incumbent generators, especially relatively inflexible plant such as coal-fired plant. This "merit order effect" results in the sudden exit of these generators with a subsequent rapid run-up in wholesale prices. 
Figure 2: Changes in generation capacity in the NEM

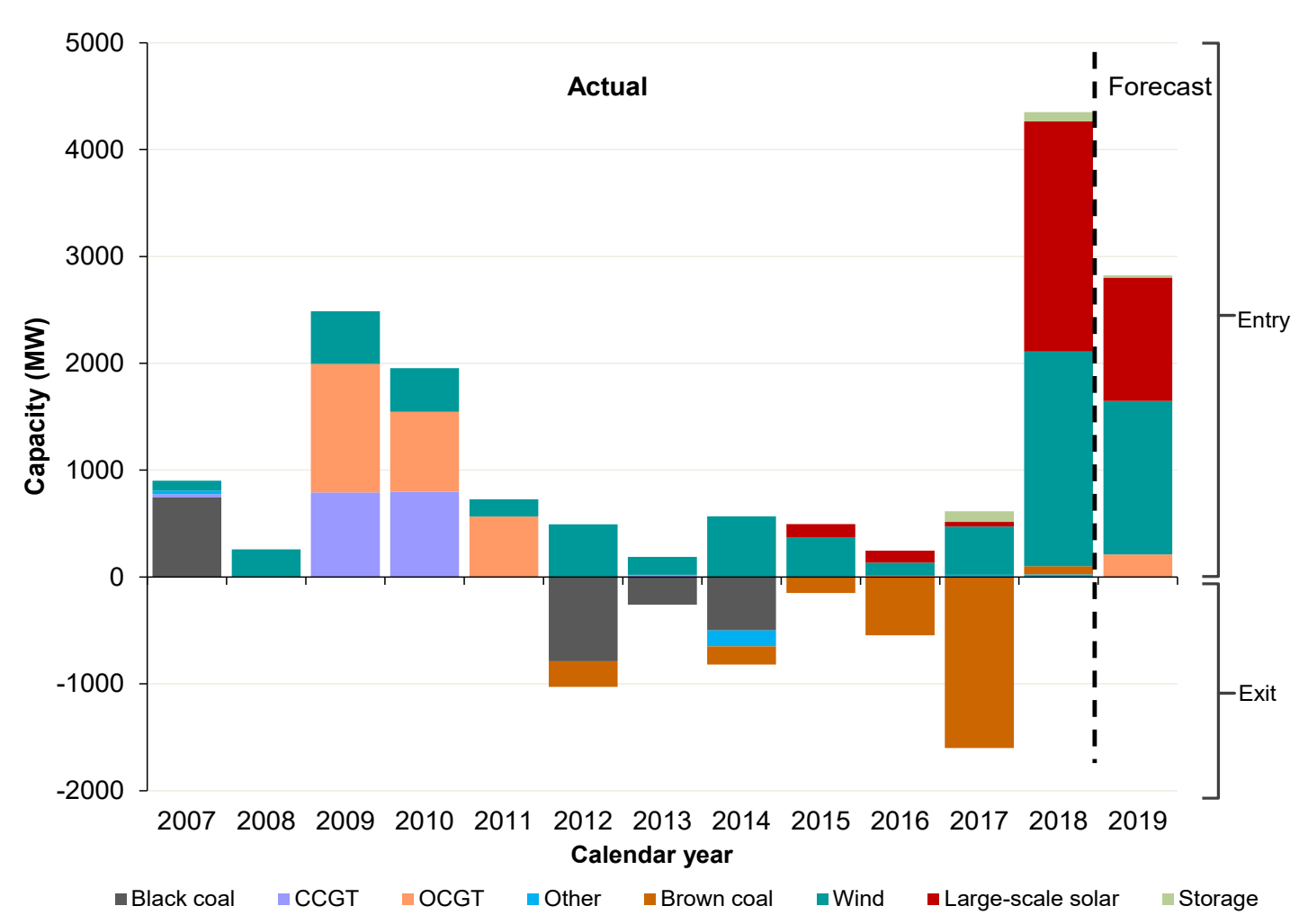

Source: Authors' analysis based on AEMO data

\subsection{Uptake of small-scale generation}

The vast bulk of small-scale generation - defined as technologies with nameplate capacity less than $100 \mathrm{~kW}$ - is rooftop PV, though other systems are included in this definition (such as smallscale wind and hydro systems). Over the past decade, there has been a significant increase in rooftop PV capacity (Figure 3) ${ }^{1}$. As at end-December 2010, installed rooftop PV capacity was less than $400 \mathrm{MW}$; eight years later it was almost 8,000 MW, an average increase of $950 \mathrm{MW}$ per year.

The increased uptake of small-scale PV has been driven by:

1. The Small-scale Renewable Energy Scheme (SRES). Like the LRET, the SRES provides a subsidy through to 2030. Unlike the LRET, there is no annual target under the SRES (i.e. it is an uncapped scheme) as the SRES is based on maintaining a constant subsidy (at or around $\$ 40 / \mathrm{MWh}$ ) paid as a lump-sum upfront to installers of eligible small-scale renewable energy systems (CER, 2018). ${ }^{2}$

2. Feed-in tariffs (FiTs) for solar PV systems at the state level. During the 2010s, most Australian states had some form of government-mandated FiT, starting with the "premium Feed-in tariffs" schemes of $\$ 440$ - $\$ 600 / \mathrm{MWh}$ in New South Wales and Victoria. To put this amount into context, households at the time were charged about $\$ 200 / \mathrm{MWh}$ for grid-sourced electricity. Nelson et al. (2012) note that the economic value of roof-top PV output, which

\footnotetext{
${ }^{1}$ Figure 3 includes all rooftop PV capacity, and therefore covers both small and larger scale PV systems.

${ }^{2}$ This includes rooftop solar PV, small-scale wind or hydro systems, solar water heaters and air-sourced heat pumps.
} 
equates to the opportunity value of that power, was found to be in the range of $\$ 52$ -

$\$ 103 / \mathrm{MWh}$, a fraction of the subsidy received. ${ }^{3}$

3. Declining prices (pre-subsidy) of PV systems. Between mid-2008 and mid-2018, prices for a $4 \mathrm{~kW}$ system fell almost 90 per cent (BloombergNEF, 2018a). ${ }^{4}$ This decline has been much greater than both the decline in feed-in tariffs and the size of the SRES subsidy - the SRES subsidy declines each year as 2030 approaches - and therefore the post-subsidy cost of PV systems has also plummeted.

The high FiTs mandated by various State governments have been discontinued, or at least are no longer available to new consumers. For new PV customers today, only Victoria and regional Queensland have government-mandated minimum FiTs.

Figure 3: Projected changes in small-scale cumulative PV capacity in the NEM

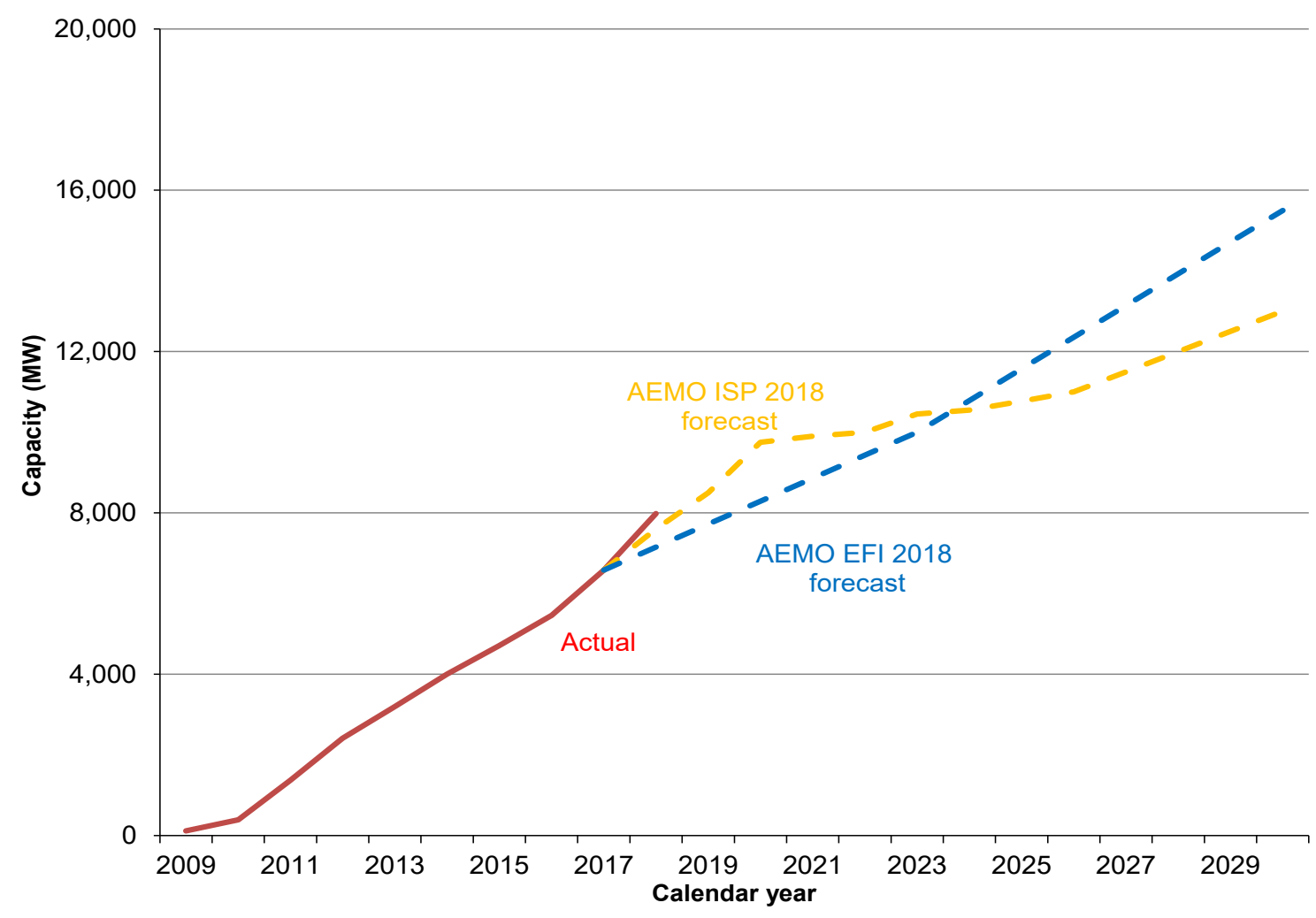

Source: Authors' calculations based on Clean Energy Regulator data and on AEMO (2018a)

In 2018, rooftop PV penetration surpassed 30 per cent of all detached dwellings in both Queensland and South Australia, with rooftop PV penetration in the other NEM states around 15 per cent (AEMO, 2018a).

Many commentators expect further uptake of rooftop PV going forward. By end-2030, AEMO (2018a) projects there will be around 13,000 MW of rooftop PV capacity in the NEM, a 60 per cent increase on end-2018 capacity. This is expected to be driven by continued declines in the relative cost of small-scale PV systems caused by a combination of:

1. Continued reductions in the costs of PV systems, especially integrated PV-storage systems, where costs are expected to fall by more than 50 per cent between 2018 and 2030

\footnotetext{
${ }^{3}$ To compound matters, these FiT schemes were highly regressive because those who accessed these schemes were mostly wealthy home-owners, whereas the schemes' costs were largely paid by low income and rental households since costs were smeared across all customers (Nelson et al., 2012).

${ }^{4}$ This is in nominal terms; in real (i.e. inflation-adjusted) terms, the decline is even greater at 91 per cent.
} 
(BloombergNEF, 2018b). In contrast, costs of PV-only systems are expected to decline 1520 per cent to 2030 .

2. The continued subsidisation of PV systems, at both the federal and state levels. For example, the SRES continues through to 2030 - despite increasing calls for it to be abolished - while the Victorian government introduced its Solar Homes Package which will come into place from 1 July 2019. From 1 July 2019, Victorians will be able to install a solar panel system for half price and pay the rest of the cost back over four years with an interest-free loan. ${ }^{5}$

A final point to note is the upwards revision to AEMO's projections of installed PV capacity; between March and June 2018, AEMO upgraded their nearer-term forecasts for small-scale PV capacity, but decreased their medium-term (i.e. post 2024) forecasts (Figure 3). This illustrates the uncertainty around future PV uptake - this uncertainty impacts the shape of future demand and therefore impacts investment decisions about both the quantum and the type (e.g. flexible or inflexible) of large-scale generation plant that might be needed today to meet residual demand tomorrow.

\subsection{Changes in grid-sourced electricity demand}

The increasing penetration of rooftop PV and changing nature of the Australian economy has led to a decline in grid-sourced (or 'operational') electricity consumption. It has also changed the profile of daily demand.

In terms of operational consumption, each region of the NEM has seen flat or falling consumption relative to 2010, with the exception of Queensland (Figure 4). In Queensland, electricity consumption rose sharply from 2014, as production from the energy-intensive LNG industry ramped up.

Figure 4: Historical and forecast operational consumption in the NEM, by region

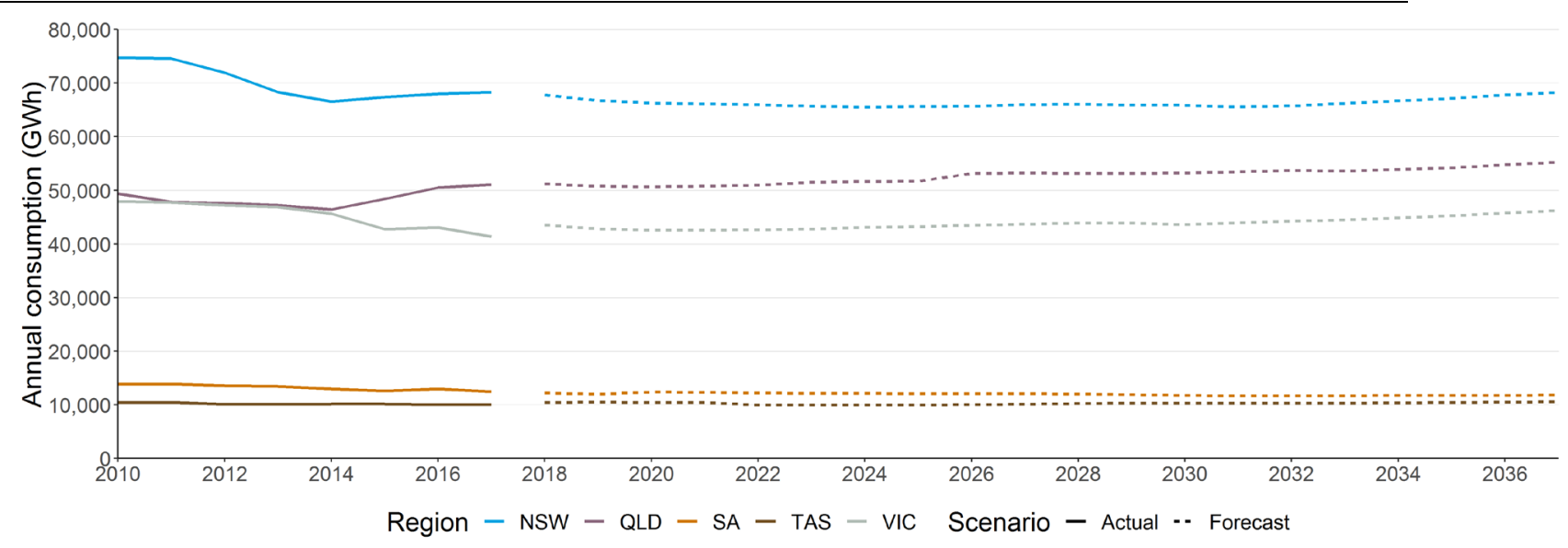

Source: $A E M O(2018 b)$

Looking ahead, several economists and industry participants expect electricity consumption to be flat or rising moderately out to the 2030s (for example, AEMO, 2018b).

This follows on from a broader trend of declining electricity consumption growth rates in the NEM over the past 50 years (Figure 5). There has been a decoupling of the traditional link between economic growth, population growth, and electricity consumption. As discussed in Sandiford et al. (2012), this reflects a combination of factors such as:

- The changing structure of the economy, with a shift from energy-intensive sectors such as manufacturing towards (non-energy intensive) services-based industries.

\footnotetext{
${ }^{5}$ https://www.solar.vic.gov.au/
} 
- A decrease in consumption amongst both large and small consumers, reflecting a response by demand to increasing electricity prices. This has occurred via both improved energy efficiency in a myriad of electrical appliances (both large- and small-scale) - such as lighting, space heating and cooling, and water heating and cooling - and increased uptake of distributed generation.

The decoupling of electricity consumption growth from both population growth and economic growth is not unique to Australia. Many other advanced, and even some developing, countries have experienced this decoupling in recent years, reflecting the factors noted above. Like Australia, some of these countries have even experienced a flat-lining of electricity consumption growth (Geller et al., 2006).

Figure 5: Growth rate of operational electricity consumption across the NEM

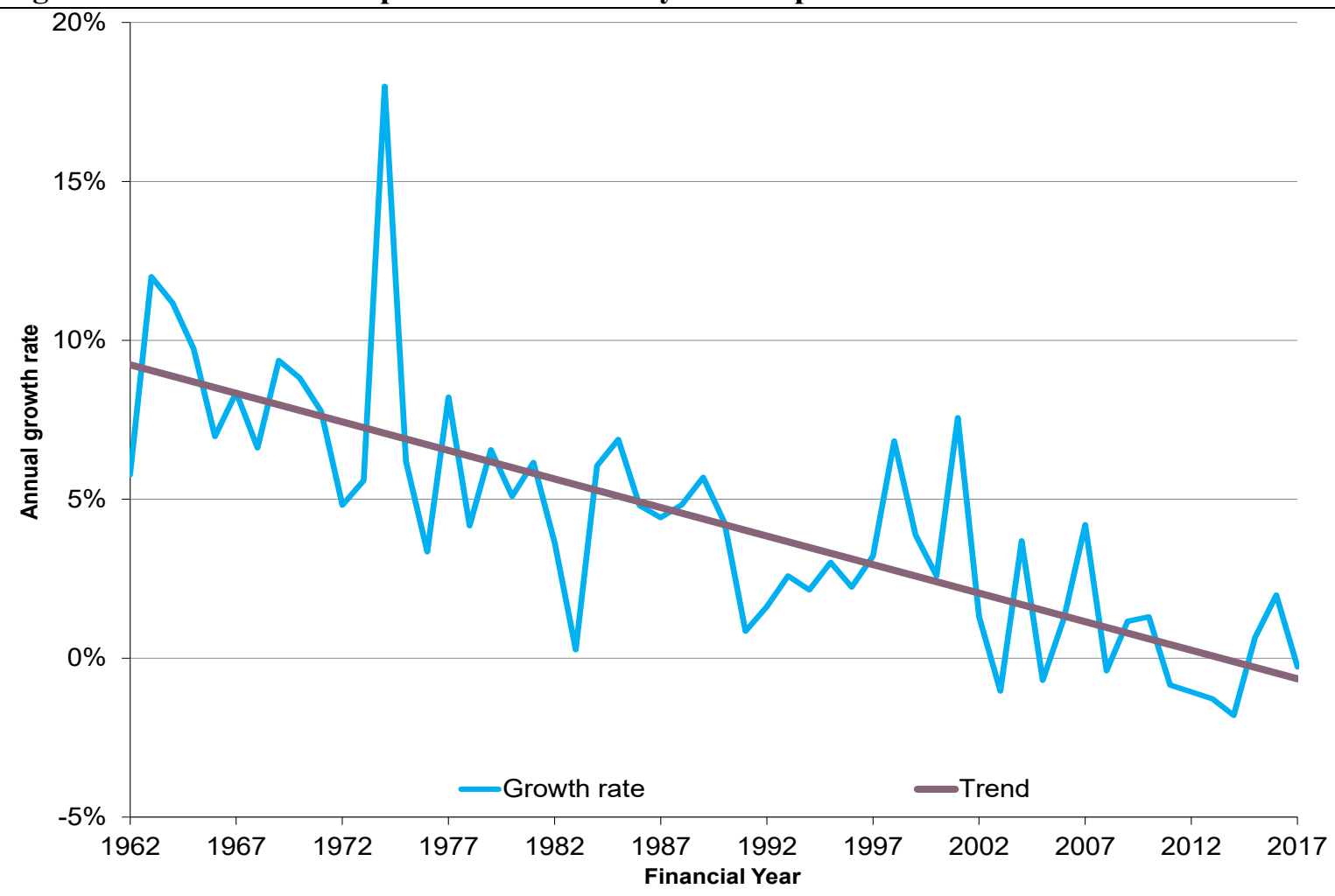

Source: Department of Environment and Energy

\subsection{Changes in residual electricity demand}

The combination of flat demand growth and growing penetration of VRE capacity has significant implications for the optimal mix of dispatchable generation that is needed in future. Renewable technologies, such as wind and solar PV have very low marginal costs, even lower than coal plants. When wind farms and solar PVs generate power, they displace generation from traditional thermal generators.

Furthermore, small-scale generation capacity in the NEM is an example of the broader class of 'non-scheduled' generators (AEMO, 2014). Non-scheduled generators do not participate in AEMO's central dispatch process and thus, regardless of their marginal costs, their output is dispatched ahead of the output from large-scale generators. ${ }^{6}$

\footnotetext{
${ }^{6}$ Large-scale (i.e. above $30 \mathrm{MW}$ ) wind and solar PV generators are classified as "semi-scheduled", while dispatchable generators (such as coal, gas, hydro, and battery storage) are classified as "scheduled". A semi-scheduled generator can supply up to its maximum registered capacity unless limited by AEMO because of network constraints (AEMO, 2014).
} 
Therefore, to determine how much 'room' there is for dispatchable (or 'scheduled') generators, residual electricity demand needs to be determined. Residual demand is defined as:

- 'native' electricity demand from large and small consumers. Native demand is electricity consumed by customers regardless of generation source (AEMO, 2019), less

- $\quad$ output from rooftop PV and other non-scheduled generation. This gives operational demand, which was discussed in section 2.3 , less

- $\quad$ output from semi-scheduled generation (i.e. large-scale VRE generation).

In addition to the variation in residual demand over the day, the increasing penetration of VRE generation is making residual demand more volatile across days.

This inter- and intra-day volatility is most evident in South Australia, the NEM region with the highest penetration of VRE generation (AER, 2018). IEA (2017) noted that only Denmark and South Australia have reached the final of the four phases of renewable energy penetration. This is where 'the system requires advanced technology to increase grid stability'. Figure 6 illustrates how South Australian residual demand has changed over time by considering the outcomes on a single day of the year (9 May) for different years. ${ }^{7}$ Between 2011/12 and 2017/18, the penetration of large- and small-scale VRE generation in South Australia doubled, from 26 per cent to 52 per cent (AER, 2018).

Figure 6: Profile of daily operational and residual demand in South Australia, 9 May by year

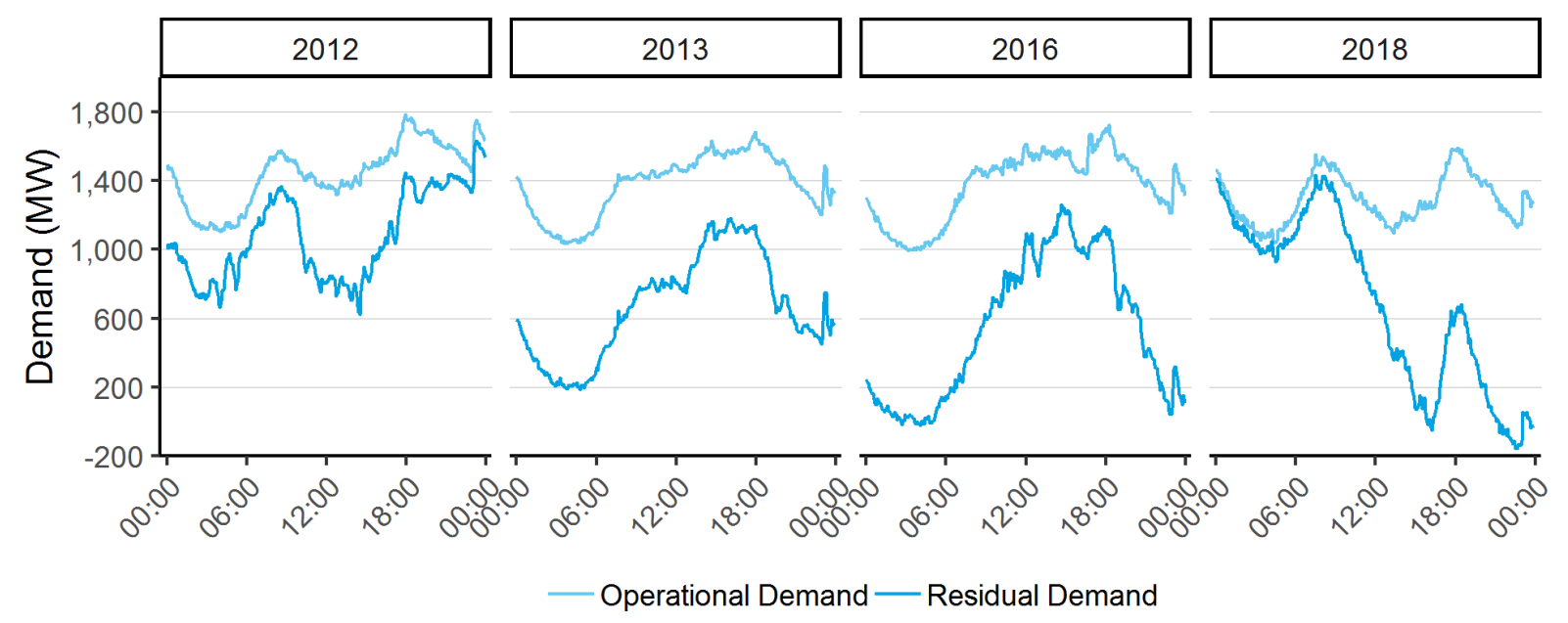

Source: Authors' analysis based on AEMO data

There are four main observations revealed by Figure 6:

1. The impact of behind-the-meter generation (solely, rooftop solar PV) in lowering operational demand during the middle of the day, often referred to as the 'duck curve'. Operational demand on 9 May 2012 was less 'peaky' than operational demand on 9 May 2018, reflecting in large part the relatively higher penetration of rooftop PV in 2018.

2. Operational demand has become more volatile, rising and falling more often over the course of the day, as the output from rooftop PV changes over the course of the day, and between different days. For example, operational demand on 9 May 2018 was quite different from operational demand the next day, even though native demand was largely the same.

3. Over time, intra-day residual demand has become more volatile, reflecting the variation in intra-day output of large-scale VRE generation - in South Australia, this is solely wind

${ }^{7}$ A choice was made to use the same day across these years were selected as they have relatively similar system demand profiles. Importantly these days occur during the same season and all fall on weekdays, removing the impact of seasonal and weekend effects on demand. 
generation. For example, residual demand on 9 May 2018 was negative in the late hours of that day, after peaking at 1,400 MW in the early hours of the day. At this time, residual demand was almost the same as operational demand, reflecting still conditions (i.e. output from wind generators was virtually zero).

4. Across days, residual demand has become more volatile, reflecting the increasing penetration of large-scale wind generation. For example, residual demand on 9 May 2018 had both higher peaks and lower troughs than residual demand on 9 May 2016, despite operational demand being highly similar across those two days.

Another way to observe the changes in residual demand is to examine the variation in residual demand across time and in the cross section. This can be captured by looking at various points on the residual demand distribution; for example, the $5^{\text {th }}$ percentile, the $50^{\text {th }}$ percentile (i.e. the median), and $95^{\text {th }}$ percentile. Figure 7 shows this for monthly residual demand in South Australia.

Figure 7: Median, $5^{\text {th }}$ and $95^{\text {th }}$ percentile of South Australian residual demand

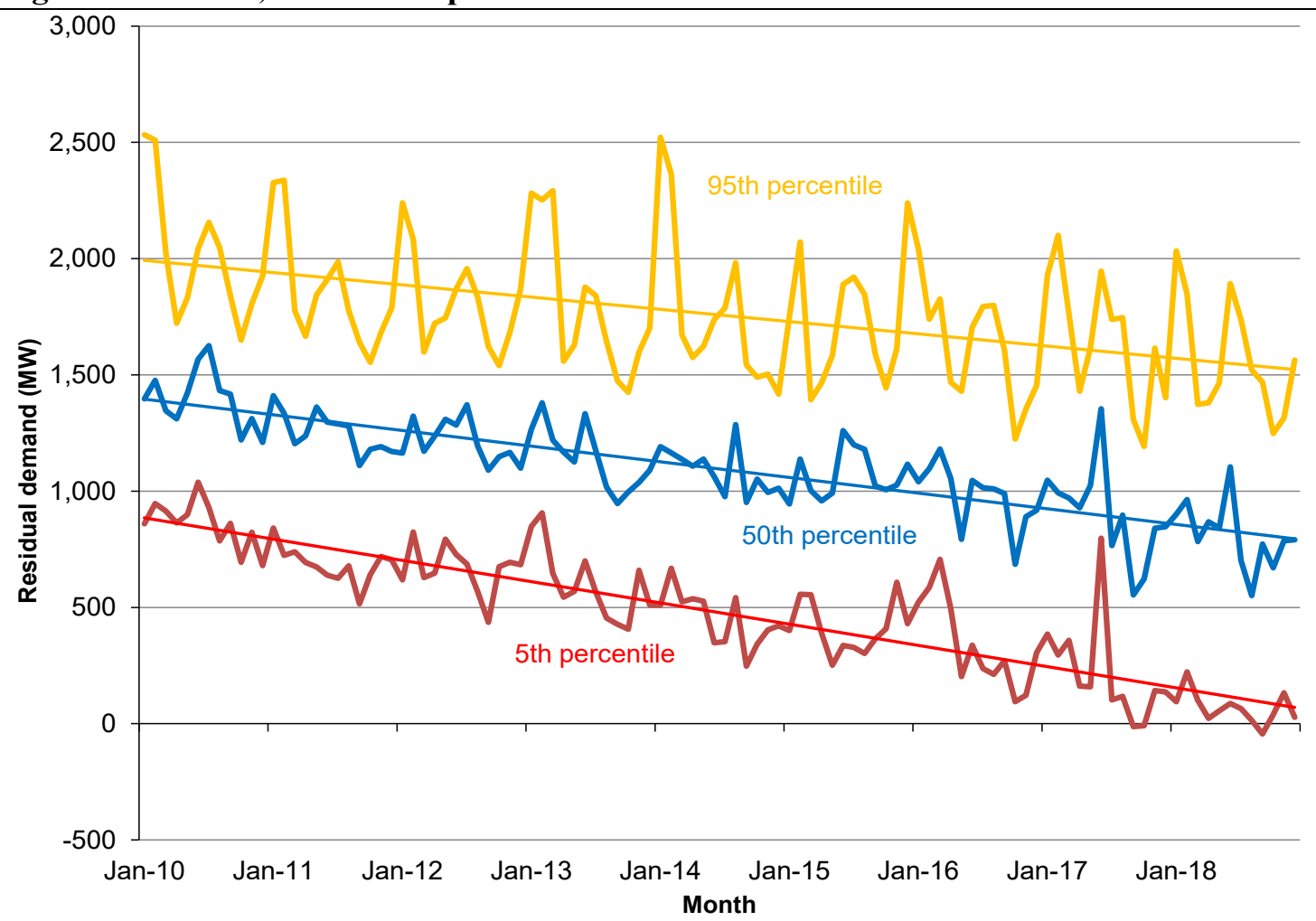

Source: Authors' analysis based on AEMO data

By including the $5^{\text {th }}$ and $95^{\text {th }}$ percentiles, we can see the change not only in the most-likely demand (i.e. median demand), but also in the extremities of the residual demand distribution. Figure 7 reveals the following three observations in South Australia's residual demand since January 2010:

1. Since 2010, the residual demand distribution has shifted to the left i.e. residual demand has fallen. This is consistent with the finding in Figure 6.

2. The residual demand distribution has become wider - residual demand at the $5^{\text {th }}$ percentile has fallen by 100 per cent - from 1000 MW to around zero - exceeding the 40 per cent decline in residual demand at the $95^{\text {th }}$ percentile (from 2,500 MW to $1,000 \mathrm{MW}$ )

3. There are an increasing number of periods where South Australian residual demand is close to zero and even negative, even at the $5^{\text {th }}$ percentile. This means minimum residual demand is even lower. 


\subsection{Implications for the generation mix}

These changes in the level and profile of residual demand, both intra-day and inter-day, have significant implications for the types of generation technologies that can reliably supply this demand in a cost-effective way. In particular, traditional technologies that are designed to operate at high capacity factors, which have correspondingly low ramp rates and high start-up costs such as coal and combined cycle gas plant - are unlikely to be dispatched to the levels required for efficient operation. It follows that these technologies will struggle to be viable as new investment propositions given the changing shape of the residual demand profile.

In contrast, flexible technologies, such as peaking gas plant, hydro, and semi-scheduled VRE coupled with dispatchable storage, are likely to be better suited to the changed profile of residual demand. Put simply, new investment in high capacity factor plant will either:

- $\quad$ substitute out existing high capacity factor thermal plant or future VRE generation. The latter is likely to apply either at the point of an inflexible plants' minimum stable generation levels or when a minimum amount of synchronous units need to be online to maintain system security, as has been increasingly evident in South Australia since mid-2016 (ESB, 2018), or

- not run, if the new plant is more expensive than existing high capacity factor plant.

The technology required today is complementary plant to that which already exists in the system and will tend to be plant that is highly responsive and more suited to lower capacity factor operation.

In a NEM context, these findings are consistent with Nelson (2018), who conducts a quantitative analysis of the optimal generation mix required to meet future residual demand upon the exit of the Liddell power station in New South Wales, and compares this mix to the generation mix expected to be in existence in 2022 immediately after Liddell's exit. ${ }^{8}$

Nelson (2018) found that there is an overweighting of slow-start 'baseload' capacity even after Liddell's exit; that is, the market does not suit ongoing operation of inflexible plants like Liddell. In contrast, there is an underweighting of intermediate and peaking capacity, with approximately 1000MW of new fast-start capacity needed to meet the residual demand gap created by Liddell's exit.

\section{Technological and policy developments in Australia's electricity markets}

\subsection{Technological developments}

Due to advances in generation and storage technology, the next decade is likely to see a change in the nature of generation investment. Sood (2018) argues that due to technological change and the dynamics of the market, in comparison to traditional generation, future generation investment is likely to:

- have smaller economies of scale (i.e. a lower minimum efficient scale) and therefore be quicker to build,

- be more modular, and

- be more portable, especially for battery storage.

Sood (2018) argues that declining minimum efficient scale is more likely for plant like solar PV and battery storage. In contrast, traditional generation plants - coal, combined-cycle gas and pumped hydro - are less likely to see declines in minimum efficient scale.

\footnotetext{
${ }^{8}$ Commissioned between 1971 and 1973, Liddell power station is located at Lake Liddell near Muswellbrook, in the Hunter Region of New South Wales, Australia. It is a black coal-powered thermal power station with four $500 \mathrm{MW}$ units for a combined nameplate capacity of 2,000 MW. However, since April 2018, its operating capacity has been assessed at 1,680 MW (Macdonald-Smith and Potter, 2018).
} 
Furthermore, some recent gas peaking generation units have been built in a highly modular fashion and at a smaller scale than was typically the case historically; for example, AGL's Barker Inlet gas plant in South Australia has twelve 17.5 MW reciprocating engines (for a total of 210 MW), with each unit capable of operating at full capacity within five minutes of starting (AGL, 2018).

This ability to 'modularise' new technologies means that these generation projects can be developed at smaller scale across different parts of the network where they are most highly valued. A lower minimum efficient scale makes these technologies quicker to build than conventional units. It also lowers barriers to entry, since the smaller scale of these projects means a much more diverse set of market participants can develop and finance these projects compared to conventional technologies. Projects can also be sold or relocated, implying a meaningful terminal value for the asset can be realised, thereby improving the economics of such investment.

Falling minimum efficient scale and lower unit sizes also lower the barriers to exit, since declining unit size lowers the impact on prices. As Caves and Porter (1976) note, lower barriers to exit can in turn lower barriers to entry.

These trends in generation investment provide even greater incentives for a more diverse set of market participants to take-up these technologies, additional to the signals created by the changing profile of residual electricity demand.

\subsection{Policy developments}

In 2017, the Australian Energy Market Commission (AEMC) made a rule to change the settlement period for the electricity spot price from 30 minutes to five minutes, starting from 1 July 2021 (AEMC, 2017). Five minute settlement provides more efficient price signals for investment in fast response technologies, such as batteries, reciprocating gas engines and demand response. The shorter settlement period provides further incentive for firm generation technologies that are fast-starting and flexible, in addition to the changes in residual demand and technological developments.

Though introduction of 5-minute settlement is still some two years away, market participants have already been considering its impact on their investment decisions. For example, Origin Energy recently upgraded its South Australian gas peaking plant, increasing the plant's capacity from $224 \mathrm{MW}$ to $240 \mathrm{MW}$ and enabling the plant to respond to 5-minute prices (Williams, 2019). In addition, AGL's Barker Inlet plant is expected to be operational in the second half of 2019.

\section{Costs of firming variable renewables}

The changes in South Australian residual demand also reveal information about the cost associated with 'firming' variable renewables. In particular, for a given operational demand profile:

- $\quad$ as the penetration of large-scale VRE generation increases, the residual demand profile becomes more variable, both intra-day and inter-day (see Figure 6),

- the cost associated with supplying residual demand increases as residual demand becomes more variable, reflecting the need for existing plant to cycle and ramp more frequently. This additional cycling and ramping has associated costs, and consequently

- the price paid for firming increases.

The price for firming can be paid either on a spot or forward (i.e. contracted) basis. In South Australia, the spot-related costs of firming large-scale wind output almost tripled between 2012 and 2018, from \$46.8/MWh to \$135.3/MWh (Figure 9). The figure shows two other South Australian prices: the dispatch-weighted price for wind generators, and the time-weighted price (i.e. the spot price used for the purposes of settlement, in the NEM). 
Over calendar-year 2018, wind generators' dispatch-weighted prices were, on average, 21 per cent below the settlement (i.e. time-weighted) price, and 42 per cent below the firming cost. The discount to the firming cost has tripled since 2012, reflecting both the increasing variability in residual demand and the increasing divergence between operational and residual demand in South Australia (see Figure 6).

Figure 8: Price of firming South Australian wind output

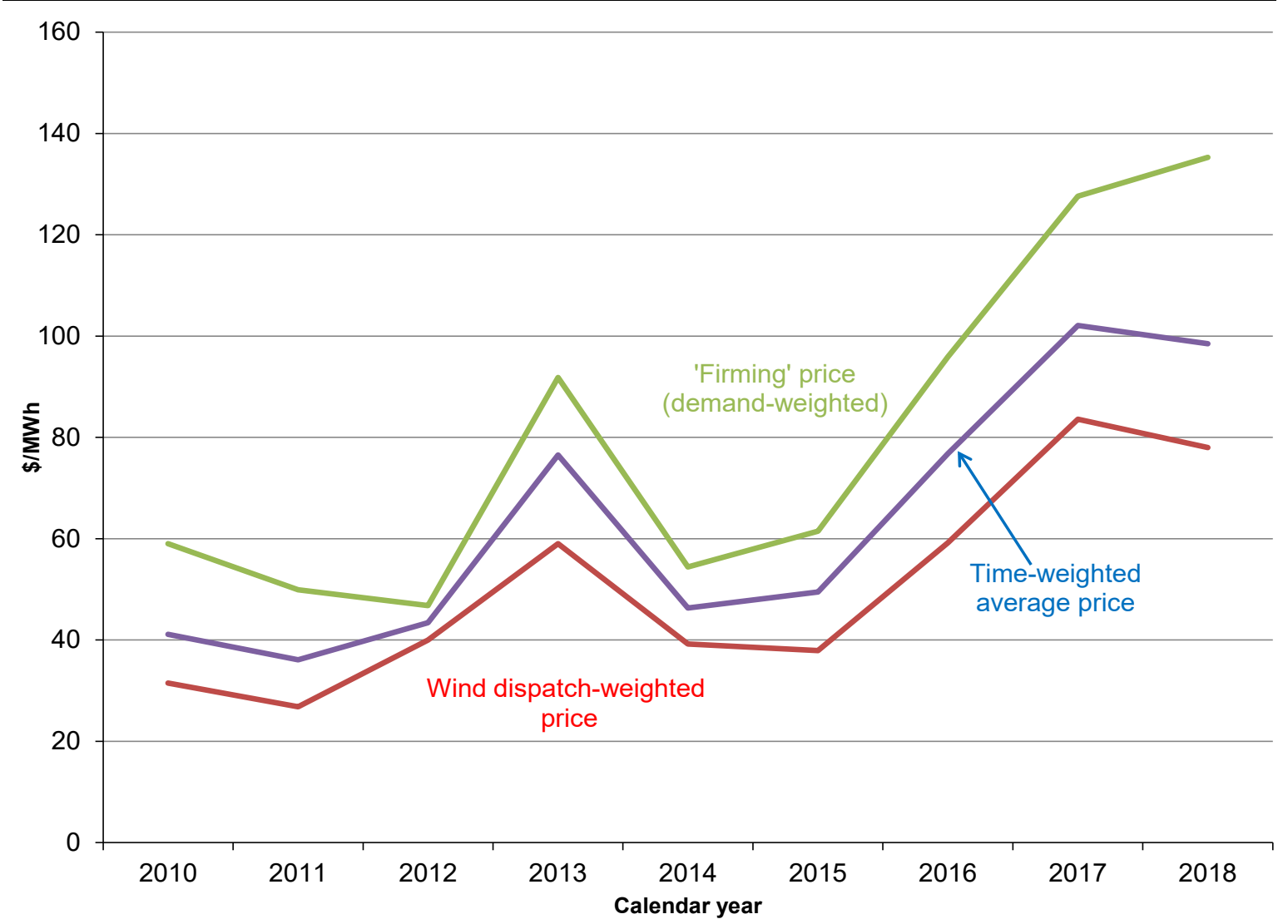

Source: Authors' analysis based on AEMO data

\section{Concluding remarks}

It is important to note that the preceding discussion focused on the flexibility dimension of different generation technologies. Overlaying emissions considerations leads to the following implications for investors in electricity generation capacity:

- For any given emissions intensity, slow-start and inflexible plant is unlikely to be as commercially viable as flexible plant.

- In a world where there is value assigned to emissions reductions, lower emissions plant is likely to be more viable than higher emissions plant, for a given ramp rate and level of flexibility. However, this need not mean that all low-emissions plant are equally viable given the need for plant with rapid response and fast-start capabilities.

These trends towards smaller plant with lower economies of scale imply a reduction in payback periods. Shorter payback periods may also be achieved by participants either via: leasing plant, or selling plant for a terminal value at some future point, presumably when the initial capital outlay has been fully paid back, but before the asset's end-of-technical life.

Given the small-scale and modular nature of plant like gas reciprocating engines, these types of plant can then be physically relocated to another part of the grid where the returns from generation are higher. 
Our discussion of the above trends in residual demand, and the implications for the generation mix, can be summarised in the following misquote of Bob Dylan's 1964 classic: The Times They Are a-Changin': ${ }^{9}$

Demand it is drawn

The curse it is cast

The slow generator now

Will later be fast

As present demand now

Will later be past

The existing mix is

Rapidly fadin'.

For residual demand and the generation mix is a-changin'.

\footnotetext{
${ }^{9}$ Lyrics for the original Bob Dylan song are available at http://www.bobdylan.com/songs/times-they-arechangin/
} 


\section{References}

AGL, 2018. Meeting peaking demand with Barker Inlet Power Station, Available online at https:/thehub.agl.com.au/articles/2018/08/meeting-peaking-demand-with-barker-inlet-powerstation Accessed online on 28 February 2019.

Australian Energy Regulator (AER), 2018. State of the energy market 2018, Available online at https://www.aer.gov.au/publications/state-of-the-energy-market-reports/state-of-the-energymarket-2018. Accessed online on 14 February 2019.

Australian Energy Market Commission (AEMC), 2017. Five minute settlement, Rule Determination, November 2017, Available online at https://www.aemc.gov.au/rule-changes/fiveminute-settlement. Accessed online on 14 February 2019.

Australian Energy Market Operator (AEMO), 2019. Demand terms in EMMS data model, Available online at http://www.aemo.com.au//media/Files/Electricity/NEM/Security_and_Reliability/Dispatch/Policy_and_Process/Demandterms-in-EMMS-Data-Model.pdf. Accessed online on 15 February 2019.

AEMO, 2018a. 2018 Integrated System Plan, A report for the NEM, July 2018, Available online at http://www.aemo.com.au//media/Files/Electricity/NEM/Planning and Forecasting/ISP/2018/Integrated-System-Plan2018 final.pdf. Accessed online on 14 February 2019.

AEMO, 2018b. 2018 Electricity Forecasting Insights, Available online at https://www.aemo.com.au/Electricity/National-Electricity-Market-NEM/Planning-andforecasting/NEM-Electricity-Demand-Forecasts/Electricity-Forecasting-Insights/2018Electricity-Forecasting-Insights. Accessed online on 14 February 2019.

AEMO, 2014. Guide to NEM generator classification and exemption, Available online at http://www.aemo.com.au/media/Files/Other/Registration\%202014/Registration\%20Final/GENE RATOR CLASSIFICATION AND EXEMPTIONS GUIDE final.pdf. Accessed online on 14 February 2019.

BloombergNEF, 2018a. 2018 Australia Behind-the-Meter PV and Storage Forecast, May 2018. Available online at https://www.bnef.com/core/insights/18683. Accessed online on 17 February 2019.

BloombergNEF, 2018b. New Energy Outlook 2018, June 2018. Available online at https://about.bnef.com/new-energy-outlook/. Accessed online on 10 February 2019.

Caves, R.E. and Porter, M.E., 1976. Barriers to exit, in: Bain, J.S., Masson, R.T and Qualls, P.D. (Eds), Essays on Industrial Organization in Honor of Joe S. Bain, Ballinger Publishing Company, Cambridge MA, pp. 241-261.

Clean Energy Regulator (CER), 2018. When does the Renewable Energy Target end?, May 2018. Available online at http://www.cleanenergyregulator.gov.au/RET/About-the-Renewable-EnergyTarget. Accessed online on 13 February 2019.

Energy Security Board (ESB), 2018. The Health of the National Electricity Market, December 2018. Available online at http://www.coagenergycouncil.gov.au/publications/health-nationalelectricity-market. Accessed online on 20 February 2019. 
Geller, H., Harrington, P., Rosenfeld, A., Tanishima, S., and Unander, F., 2006. Polices for increasing energy efficiency: Thirty years of experience in OECD countries, Energy Policy, 34(5), 556-573, https://doi.org/10.1016/j.enpol.2005.11.010

Institute of Energy Economics and Financial Analysis (IEEFA), 2018. Power-Industry Transition, Here and Now - Wind and Solar Won't Break the Grid: Nine Case Studies, February 2018. Available online at http://ieefa.org/wp-content/uploads/2018/02/Power-Industry-Transition-Hereand-Now February-2018.pdf. Accessed online on 05 March 2019.

International Energy Agency (IEA), 2017. Getting Wind and Sun onto the Grid: A Manual for Policy Makers, April 2017. Available online at https://www.iea.org/publications/insights/insightpublications/Getting_Wind_and_Sun.pdf. Accessed online on 05 March 2019.

Macdonald-Smith, A., and Potter, B., 2018. The fight about AGL's Liddell power station explained, Australian Financial Review, April 11 2018, Available online at https://www.afr.com/business/energy/electricity/the-fight-about-agls-liddell-power-stationexplained-20180410-h0yju5. Accessed online on 19 February 2019.

Nelson, T., 2018. The future of electricity generation in Australia: A case study of New South Wales, The Electricity Journal, 31(1), 42-50, https://doi.org/10.1016/j.tej.2018.01.003

Nelson, T., Simshauser, P., and Nelson, J., 2012. Queensland Solar Feed-In Tariffs and the MeritOrder Effect: Economic Benefit, or Regressive Taxation and Wealth Transfers?, Economic Analysis \& Policy, 42(3), 277-301, https://doi.org/10.1016/S0313-5926(12)50030-5

Sandiford, M., Forcey, T., Pears, A., and McConnell, D., 2015. Five years of declining annual consumption of grid-supplied electricity in Eastern Australia:causes and consequences, The Electricity Journal, 28(7), 96-117, https://dx.doi.org/10.1016/j.tej.2015.07.007

Simshauser, P., 2018. On intermittent renewable generation \& the stability of Australia's National Electricity Market, Energy Economics, 72(C), 1-19, https://doi.org/10.1016/j.eneco.2018.02.006.

Simshauser, P., and Nelson, T., 2013. The Outlook for Residential Electricity Prices in Australia's National Electricity Market in 2020, The Electricity Journal, 26(4), 66-83, https://doi.org/10.1016/j.tej.2013.04.008

Sood, R., 2018. NEM structure in light of technology and policy changes, A report for the Australian Energy Council, Frontier Economics, 13 December 2018. Available online at https:/www.energycouncil.com.au/media/14945/20181213-final-report-advice-on-nem-structurein-light-of-technology-change-stc.pdf. Accessed online on 18 February 2019.

Williams, P., 2019. Quicker power as Origin upgrades, The Australian, 07 January 2019, 13-14. 